\title{
THE DEVELOPMENT AND ADOPTION OF IMPROVED LAND MANAGEMENT PRACTICES UNDER THE INTENSIFIED AGRICULTURAL PRODUCTION SYSTEM IN ANAMBRA STATE, NIGERIA
}

\author{
Anaeto, C. F., Matthews-Njoku, E. C. And Onu, D. O
}

\begin{abstract}
In present day Anambra State, increased population densities, growing food and market demands, urbanization, proximity to major road infrastructure, soil conditions and deterioration in quality of land for agricultural purposes have brought about reduced agricultural productivity. These changes have resulted to increasing socio-economic pressure on land and differential access to farmland and intensification of cultivation with farreaching consequences for land-use management practices and the sustainability of the agricultural system. Severe soil fertility and productivity decline, ecological damages including soil erosion losses, flood and gullies are some of the out comes of the uncontrolled land-use and agricultural intensification in the state. These problems might worsen in future due to the fragile, heavily weathered and leached nature of the soil. This situation can only be corrected by the incorporation of improved soil conservation practices in our farming system through acceleration of farmer's adoption rates of the recommended innovations.
\end{abstract}

\section{Key words: Adoption, Improved Land Management Practices, Intensified Agricultural Production System}

\section{INTRODUCTION}

Land-use management is the world's most important environmental and productivity problem (UN.1984). In Nigeria, one of the most serious problems of land-management is soil erosion. Soil erosion constitutes one of the greatest environmental and productivity problems of the moment, causing an estimated 30 million tones of soil loss annually (Ofomata 1981). Most of the severe and frightening soil erosion problems and catastrophes in Nigeria are found in many parts of South Eastern region where population densities and least land per capital rank among the highest in rural Africa (Clarke 1967, Lageman, 1971). In this region, more than $50 \%$ of the estimated 30-millon tones annual soil loss in Nigeria through erosion is obtained (Onu, 1991). Also about $70 \%$ of the region's total land areas of $78.612 \mathrm{~km}$ are affected by different and varying degrees of erosion menace ranging from mild sheet wash to deep gullies.

The erosion problem is highly pronounced in Anambra State, which is one of the nine States of the Agro-ecological zones covered by South Eastern Nigeria. About 30\% of Anambra State land cannot be cultivated either because it is too elevated to support the growth of crops or that land has been rendered useless by soil gully erosion as well as other forms of land degradation (Egboke and Nwafor, 1994). Most of the erosion problems in Anambra State emanates from the fact that the hitherto rain-forest belt found in some parts of the state has given way to derived savannah (grass land) vegetation because of uncontrolled human activities of urbanization, competitive and unregulated housing, indiscriminate cutting down of trees and uncontrollable movement of heavy duty vehicles across the state as gateway to all the eastern states.

The soils of Anambra State have sedimentary origin with sand stones and shales as the two dominant parent materials (Egboka and Nwafor 1994). The rain comes in the form of intensive violent showers and where soils are bare or partially covered by vegetation, the violent showers constitute an active agent of geologic erosion. The State has already lost over $20 \%$ of her landmass to erosion and more then 500 erosion sites discovered (Nzekwe 1995). 
The massive soil loss in Anambra State results in severe ecological damage, severe soil fertility depletion, loss of soil structure, decline in agricultural productivity and famine (acute food shortage). Both physical and anthropogenic factors as well as deficient agricultural practices are believed to be responsible for the high erodability of the efforts made to control erosion menace in Anambra State. The focus of this paper therefore is to review different efforts made to control erosion menace in Anambra State and adoption of those efforts or measures with a view to improving Land-use management and agricultural development in Anambra State.

In order to address the agricultural intensification problem and land quality in the State, the Federal Government and State Government as well as some donor agencies have developed policies, programmes and projects aimed at accelerating the adoption, use and development of improved land-use management practices among farmers in Anambra State with a view to sustaining agricultural development. In order to arrest the menace of soil and set the stage for a new approach to land-use and land management, the Anambra State Government after a fresh study of the problem and following its policy of improving the living conditions of both urban and rural dwellers, decided in 1986 to set up a Task Force to handle erosion menace in the in the State.

The task force was charged with the following functions/responsibilities:

- $\quad$ To re-examine previous studies on soil erosion control in Anambra State and work out a phase implementation programme.

- $\quad$ To enlighten the public on causes of erosion and control measures to be taken to prevent or arrest its spread.

- $\quad$ To provide extension services to farmers in respect of proper farming practices for checking sheet erosion menace.

To monitor regularly and identify incipient erosion sites for prompt remedial measures

- To identify and classify marginal lands which for purposes of conservation will be treated as forest reserves.

The result of these efforts is the development and recommendation to farmers for use through extension services, the following improved soil conservation techniques viz

- $\quad$ Organic/plant residue management

- $\quad$ Correct use of fertilizer

- Crop rotation

- Mulching contouring

- $\quad$ Contour ridging and bounding. (i.e. planting along the contour)

- $\quad$ Strips cropping

- $\quad$ Conventional tillage practices

- $\quad$ Tie mounds/ridges/ploughing,

- $\quad$ Stop wash lines

- $\quad$ Tree planting

- $\quad$ Alley cropping

- $\quad$ Use of leguminous cover crops or grass

- $\quad$ Terracing

- Inter cropping of arable crops with tree crops and similar practices (Anambra State ADP 1991)

Suitable plant species for soil fertility, restoration and erosion control were recommended by the Anambra State task force on erosion to include:

- $\quad$ Azadirachta indica (Neem)

- $\quad$ Berlinia grand flora (Ububa) 


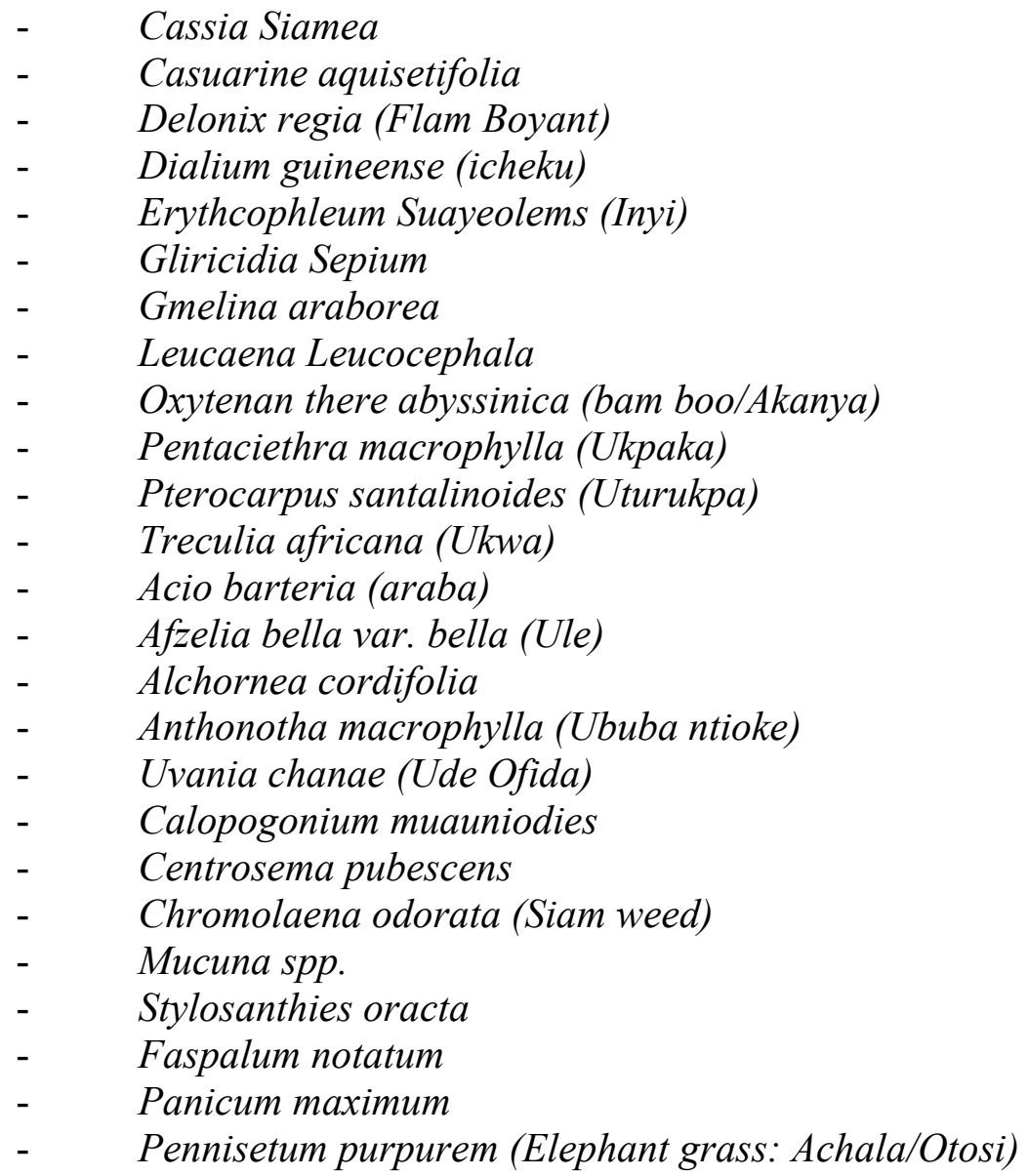

The task force equally recommended the following erosion control measures viz:

- $\quad$ Adopt tree planting as a standard practice especially wherever land is marginal and erosion prone.

- Adopt partial clearing in preparing sites for farming so that useful trees are retained, which will play beneficial roles including nutrient recycling, providing protective cover, stabilizing the soil while at the same time, providing economic products.

- $\quad$ Burning of sites for purpose of farming is destructive to the soil and also bush burning is destructive thus natural forests, plantation and farms should therefore, as a matter of necessity be protected from fire.

- $\quad$ Slashes produced during land clearing should be ploughed back into the soil while fast-growing trees and shrubs should be planted and be used as fodder during the dry season.

- $\quad$ Farming on water catchment areas and steep slopes should be avoided but when absolutely necessary, should be done with contour ridging and bonding in order to conserve moisture and reduce surface run-off. When the slope is long, then it is necessary to employ terraced farming as this also reduces the speed of run-off.

- Avoid farming on such water catchment areas and stream banks in order to prevent silting of streams.

- $\quad$ Avoid farming close to the edge of the roads.

- $\quad$ Adopt alley farming where possible as this serves to stabilize the soil and act as windbreak.

- Adopt inter-cropping of arable crops to ensure that the soils are at all times protected by vegetative cover.

- $\quad$ Trees established to protect sites from erosion must never be cut down for 
firewood; stakes etc except under planned and control forest management.

- Quarrying of sand, gravels and laterite from roadside, flood channels and floor plains must be avoided in erosion-prone areas as these activities open up channels for erosion.

- In all industrial establishments and community projects such as hospitals, schools, markets and roads constructions, adequate soil conservation measures should be taken including adequate drainage channels and other engineering structures, as well as tree planting and grassing of relevant areas with grasses like Vetiver and carpet grass.

- $\quad$ Floodwater from compounds should be allowed to escape as run-off but should be trapped in strategically located soak-away or catch pits (within or outside the compound).

- $\quad$ People living in erosion-prone areas should also channel floodwaters and rain waters from their houses down to the flood plains, streams, rivers or lakes.

Floodwaters may also be diverted to level ground farmlands where the water is allowed to drain slowly into the surface.

Do not grade roads as grading loosen the soil for wind and water erosion and lower the elevation of the ground surface.

- $\quad$ Rather fill up the potholes or flood channels with laterite and compact the soil on the road to a hardened mass.

- $\quad$ In building or rebuilding rural roads, raise the ground surface so that water can runoff at the sides.

\section{ADOPTION/USE OF SOIL CONSERVATION MEASURES BY FARMERS IN ANAMBRA STATE:}

Over the years, soil erosion/conservation measures aimed at land-use management have been introduced to farmers in Anambra State. According to ministry and ADP sources, methods used in disseminating information on these control measures to farmers include the use of extension staff to teach the farmers, use of radio/television, seminars, exhibitions, handouts, farm visits and personal contacts by farmers with specialists. Adoption of new conservation practices is a function of behavioral change. The initial or fore-most step towards the adoption of a new practice is the knowledge that the innovations are available to the farmers. Adoption may be explained as a decision to make full use of information as the course of action among alternatives. Lion Berger (1960) regards adoption as the full-scale integration of a new idea, product and practice into an on-going operation. Rogers and Shoemaker (1971) believe that it is a mental process through which an individual passes from first knowledge of an innovation to a decision to adopt or reject and to confirmation of this decision by continuous use.

Findings of studies conducted by several researchers including Anaeto (1985), Onu (1990) and Uwakah (1984), found that the significant variables which influence the adoption behaviours of farmers were the education, age, contact with change agents, occupational status, profitability of programmes, farm size, family size, farm income, access to market facilities, characteristics of infrastructure, values, belief, culture and attitudes which every society holds.

The adoption of innovation is a very uneven process, varying geographically from farmer to farmer and region to region or country to country. Rochin (1979) identifies five general types of factors affecting the adoption of new technology by farmers as:

attributes of the adopter such as technical skills, attitudes towards change and risk, income level, aspirations and confidence.

- $\quad$ Aspect of the technology such as economic profitability, divisibility, complexity, 
communicability and technical appropriateness.

- Characteristics of the economy such as government policy.

- $\quad$ Features of the environment at the farm level such as farm resources constraint and socio-cultural factors.

Risks and uncertainties.

In line with what Rochin explained, Perrin and Winkleman (1976) and Pachico and Ashby (1983) stated that the location specificity of the performance of new technology is a major factor determining whether farmers adopt and benefit from potential improvement. Pachico and Ashby noted that a farmer considering adoption of new technology faces the real task that it may prove to be unsuited to local consideration. They listed some important agroeconomic consideration, which enter the farmer's calculations as:

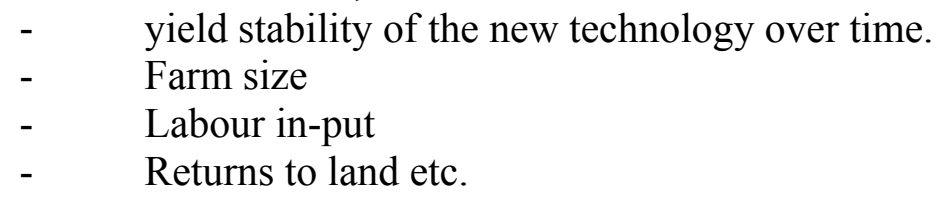

The findings of Nweke and Akorhe (1983) on the determinants of adoption of new rice technology also support the view that the adoption or rejection of a given technology depends on several factors. First is the profitability of the innovation. Second is the ready availability of the material component and if the farmers have the means to purchase them. They presented that adoption is a function not only for the extension method parse but also of resources available for extension work, of characteristics of farming population, the attributes of the given technology, the availability of the material components as well as the net value of the technologies in the farm production activities.

Much is already known about the effects of the attributes of the sender on the transfer and adoption of innovation. It has therefore, become important to recognize new dimensions in the factors that influence the rate and level of these behavioural change process.

In integrating the theories and research findings of numerous scholars, four groups of variables have been shown to determine the adoption of new technologies such as soil conservation. These factors include:

$\begin{array}{ll}- & \text { Technology factors } \\ \text { - } & \text { Agronomic factors } \\ \text { - } & \text { Economic factors } \\ \text { - } & \text { Social/diffusion types factors }\end{array}$

In developing this model, theories and findings of experts like Lionberger (1960), Rogers and Shoemaker (1971), Lagemann (1971), Nweke and Akorhe (1983) Pachico and Ashby (1983) and Leagans (1971) were integrated. The emphasis is placed on the innovation and its attributes and their effects on adoption. It shows that technology attribute, agronomic and economic factors interact with the intervention of extension communication to determine the rates and levels of farm practice adopted. It also shows that exposure to soil conservation information environment is a basic condition affecting farmer's innovation behaviour. It shows also that change can only take place when the individual is made aware that his present situation is at variance with his objectives.

Farmers in Anambra State in the past depended on shifting cultivation or bush fallow system for maintaining the fertility of their farmlands. Presently, such factors as population pressure, land tenure changes, economic constraints, urbanizations, local power relations, farm specific characteristics and ecological constraints have led to changes in farmers' access to farm land consequently these changes have affected land-use patterns and intensification of cultivation with far-reaching influence on the stability of traditional follows and sustainability of agricultural productivity. It is therefore, in view of this that Improved soil conservation 
technologies were recommended to farmers as protective measure against the destruction of the agricultural production resource base (land) and other related problems of agricultural intensification in Anambra State.

In spite of the favourable soil conservation measures introduced to farmers in Anambra State, studies by Anaeto (2000), Onu (1991), Onwujiobi (1995), had shown that there has not been enough impact on farmers as far as land-use management is concerned. The level of favourable conservation behavioral change is unsatisfactory to cope with the increasing agricultural intensification problems so as to ensure sustainable production system in the long run. It was found that farmers' adoption decisions in Anambra State were associated with their personal and social characteristics, information source use and other socio-cultural factors, land-use intensity indicators, other agro-ecological factors, technological attributes and economic factors.

\section{CONCLUSION}

Based on the findings, it was established as follows:

That severe soil infertility, productivity decline and ecological damages in Anambra State are all as a result of land degradation due to poor soil management.

- $\quad$ That the situation could be checked by the acceptance and adoption of soil management.

- $\quad$ That any policy on agricultural development must consider the special nature of the farmers, their indigenous knowledge (IK) and other factors for it to succeed

- $\quad$ That there is a danger of uncertainty of future production, especially under the tropical conditions of very fragile, heavy leached and weathered soils still uncontrolled up-to-date. This therefore calls for basic need setting for adoption and incorporation of appropriate soil conservation technologies within the faming system in Anambra system is to be ensured.

- $\quad$ That exposure to and frequency of use of information source increased knowledge gain and was crucial in improved soil conservation adoption decisions of farmers.

- $\quad$ That farmers' decisions on adoption of improved soil conservation practices was related to their personal, socio-cultural factors and economic factors.

- That if every one in Anambra State today should start to observe the recommended measures of erosion control and know that Anambra State has no other land mass anywhere in the world, the fight against erosion menace would be won.

- $\quad$ That appropriate land-use and land-management by all will save Anambra State from further devastation by gully erosion and the effort to control existing gullies will yield fruitful results.

\section{RECOMMENDATIONS}

Based on the major findings in this study, the following recommendations were made:

- $\quad$ Adequate grants and incentives should be made available to farmer to help them sustain the financial involvement in soil erosion control.

- $\quad$ Soil conservation practices should be designed to suit farmers' situations and needs

- $\quad$ Farmers should be encouraged to form credit and co-operative societies to help themselves.

Since farmers' evaluation of new technologies in term of desirable, technical, economic, agronomic and social attributes influence their adoption decision; it is therefore, necessary that social, agronomic and economic experts must be constituted into a research team to undertake on immediate study of the farmer 
adopter clientele.

- $\quad$ The Extension System must be subjected to make it mandatory for the personnel to create relevant and useful demonstration plots for trying out improved soil conservation technologies. This will show farmers the needs for and superiority of the new technologies over their old methods. This therefore, calls for result and method demonstration plots

- The increasing agricultural intensification problems in the state calls for an urgent inventory and documentation of the conditions of agricultural soils of each community and an assessment of necessary technology packages to overcome the problems.

- Government both Federal, States and Local governments should be involved honestly in the fight against erosion.

Communities/Town Unions should also be involved such that erosion stressed or disaster areas should be allowed to (a) Lie fallow to recover naturally (b) be declared a forest reserve (c) be used as experimental/demonstration plots (d) be planted up with leguminous cover crops.

Schools and colleges should be encouraged to set up anti-erosion clubs and they could also plant fruit trees to serve as anti-erosion measure, food items and wind breaks.

\section{REFERENCES}

Anaeto, C.F. (1985): Factor Influencing Farmers Response to Extension Programmes In Ogbaru District of Onitsha L.G.A Anambra State. B. Agric. Project Work UNN. Pg. 16 \& 44.

Anaeto,C.F. (2000): The Effect of Anambra State Agric. Extension Service on Farmers Adoption of Improved Soil Conservation Technologies. M.SC. Thesis. FUTO.

Clark, W. C (1967): "From Extensive to Intensive Shifting Cultivation. A Succession from New Guinea" Ethnology 5. Pg 347-359.

Dudal, R. (1982): "Land degradation in word perspective" Journal of soil and water Conservation. 37 (5) Pg. 245-249.

Egboka, B. and Nwafor U.E.J. (1994): River boundary Agric. Lands in Anambra State Agricultural Forum, National Light News paper August $10^{\text {th }}$ P. 11 . Guide on Soil Erosion Control in Anambra State (1986) Vol. 1 Anambra State Task Force on Soil Erosion Control.

Lagemann, F. (1971): Traditional Africa Farming Systems in Eastern Nigeria: An Analysis of reactions to increasing population pressure. Welfgorm Verog on Nunchan.

Leagans, J.P. (1971): Extension Education and Modernization in behavioural change in Agriculture. J.P. Leagans and C. P. Loomis (Ed) Cornel University Press Thaca pp 101 147

Lion Berger, H.F. (1960): Adoption of New ideas and practices. Iowa State University Press, Ames Iowa. P. 96-97.

Nweke, F.I. and J.A. Akorhe (1983)"'Determinants of Adoption of New Technologies Among Small Holders and Implementations for Administration of Transfer 
Nzekwe, Amaechi (1995); "Erosion. Village Face Extinction” Utuh Community Puts Government on Red Alert. Nigeria Home News Magazine No1Oct. - Nov. $2^{\text {nd }} 29-30$.

Onu, D.O. (1990): Communication and Adoption of Improved Soil Conservation Technologies by Small Farmers in South-Eastern Nigeria; Evidence From Imo State: A research report for the second ford Foundation/Social Science Council of Nigeria.

Onu, D.O. (1991); Factors associated with small-scale farmers' adoption of improved Soil conservation technologies under intensified Agric. In Imo State, Nigeria. PhD Thesis UNN.

Onwujiobi, J.A.(1995): The attitude of farmers towards the adoption of soil conservation Practices: A case study of Onitsha Agric. Zone of Anambra State. B.Sc Thesis. Dept of Agric. Economics/Extension, University of Calabar.

Pachico, D and J. Ashby (1983): Stages in Technology Diffusion Among small farmers. Biological and Management screening of a new rice variety in Nepal. Agricultural Administration. pp 13: $23-38$.

Perrin, R. and D. Winkleman (1976): Impediments To Technical Progress on Small versus Large farms “American Journal of Agricultural economics” 58: pp 788 - 824.

Rochin, R.I. (1979): Why Small Farmers do not Adopt and Utilize New Technology. Davis, California, USA. Department of Agricultural Economics.

Uwakah C.T. (1984): Farmer's reaction to the use of fertilizer and other manures in two Eastern State of Nigeria. Summaries/Abstracts of Agric. Extension, Adult Education and Rural Development Studies. No 1 Aug. pp $44-46$. 